\title{
Fibrodisplasia osificante progresiva. Reporte de un caso y revisión de la literatura
}

\author{
Progressive ossifying fibrodysplasia. Case report and \\ literature review
}

\author{
Saida Storm', Gloria Martínez' ${ }^{1}$ Laura Godoy ${ }^{1}$
}

\section{RESUMEN}

La fibrodisplasia osificante progresiva (FOP) es una enfermedad del tejido conectivo de etiología desconocida, de herencia autosómica dominante que se caracteriza por calcificaciones progresivas de las fascias, aponeurosis, ligamentos, tendones y tejido conectivo intersticial del músculo esquelético. Su prevalencia es de 1:2.000.000.

Presenta desde el nacimiento morfología anormal del primer metatarsiano. Las osificaciones heterotópicas por lo común se hacen evidentes recién alrededor de los 5 años, posteriores a un trauma en los tejidos blandos. El compromiso funcional es progresivo y altamente incapacitante.

Presentamos el caso de un niño de 6 años quien desde el año de edad inició las lesiones en las zonas de traumatismos, al comienzo acompañadas de dolor y signos inflamatorios que luego se petrificaban. Presentaba hállux valgus corto bilateral y se pudo corroborar la presencia de la misma malformación en un tío materno.

Palabras claves: Fibrodisplasia osificante. Hallux valgus. Osificación heterotópica, Pediatría.

\section{INTRODUCCIÓN}

La fibrodisplasia osificante progresiva (FOP) es una rara enfermedad de etiología desconocida, un trastorno autosómico dominante del tejido conectivo, que se caracteriza por calcificaciones progresivas de las fascias, aponeurosis, ligamentos, tendones y tejido conectivo intersticial del músculo esquelético $^{(1-3)}$. Su prevalencia es de 1:2.000.000 ${ }^{(4,5)}$.

\begin{abstract}
Progressive ossifying fibrodysplasia (POF) is a connective tissue disease of unknown etiology, of autosomal dominant inheritance characterized by progressive calcifications of fasciae, aponeurosis, ligaments, tendons, and interstitial connective tissue of skeletal muscle. Its prevalence is 1: $2,000,000$. Abnormal morphology of the first metatarsal is present at birth. Heterotopic ossifications usually become apparent only about 5 years after a soft tissue trauma. The functional compromise is progressive and highly disabling.

We present the case of a 6-year-old boy who, beginning at one year of age, developed the lesiones in injured areas, with subsequent petrification, initially accompanied by pain and inflammatory signs. He presented bilateral short hallux valgus and we corroborated the presence of the same malformation in a maternal uncle.
\end{abstract}

Keywords: Ossifying fibrodysplasia, hallux Valgus, heterotopic ossification, Pediatrics.

Una manifestación más temprana, presente desde el nacimiento, es la morfología anormal del primer metatarsiano $^{(5)}$. Las osificaciones heterotópicas por lo común se hacen evidentes alrededor de los 5 años, usualmente precedidas por un trauma en los tejidos blandos. El compromiso funcional es progresivo y se produce por anquilosis extrarticular de las

\footnotetext{
${ }^{1}$ Ministerio de Salud Pública y Bienestar Social, Hospital Pediátrico “Niños de Acosta Nu”. San Lorenzo, Paraguay.

Correspondencia: Laura Godoy. Correo: legodoys@gmail.com

Conflicto de interés: Los autores declaran no poseer conflicto de interés

Recibido: 28/01/2019Aceptado:22/02/2020

DOI: https://doi.org/10.31698/ped.47012020008
} 
articulaciones. Es altamente incapacitante ${ }^{(6)}$.

\section{CASO CLÍNICO}

Niño de 6 años, consulta por múltiples tumoraciones ubicadas en cuello, tórax y región lumbar.

Antecedentes patológicos: las tumoraciones tienen 5 años de evolución, se iniciaron en cuello, al inicio, acompañadas de dolor, con signos inflamatorios e impotencia funcional. Después del cuadro inflamatorio quedaban de consistencia pétrea, sin dolor, limitando los movimientos. Con el tiempo se extendieron a la región escapular, torácica y lumbar (Figura 1).

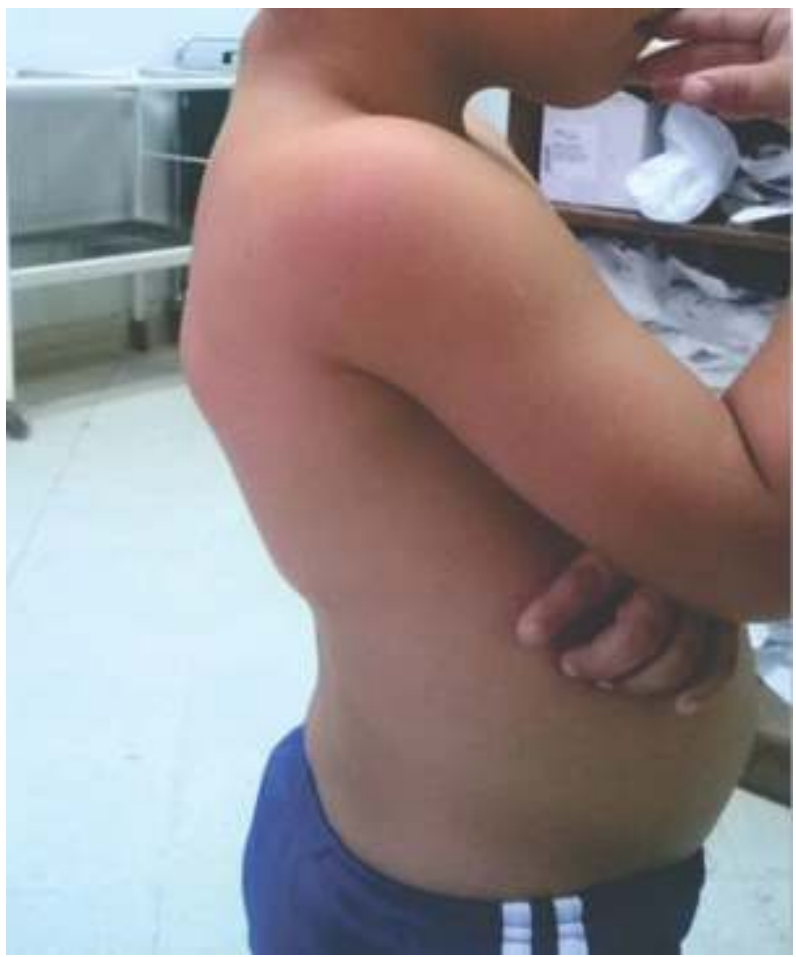

Figura 1. Lordosis y tumoraciones en región cervical, interescapular de consistencia pétrea.

Examen Físico: Se palpan tumoraciones sólidas, pétreas, inmóviles, no dolorosas, sin signos inflamatorios en región cervical, que se extendían desde tórax hasta región lumbar de diferentes tamaños (la mayor mide $4 \times 5 \mathrm{~cm}$ ) y en los pies, hállux valgus corto bilateral. En los hombros la abducción era de $45^{\circ}$ (Figura 2 ).

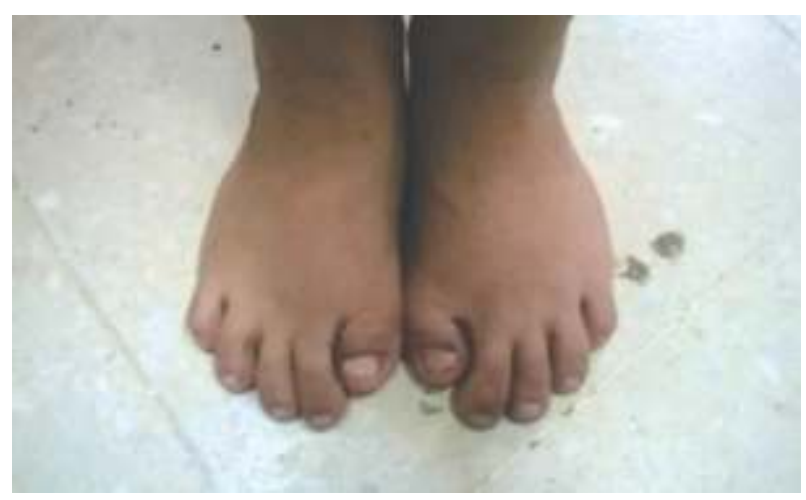

Figura 2. Aspecto clínico de los pies de la paciente con un hállux valgo corto bilateral. Los defectos del hállux son un signo temprano y patognomónico en todos los casos de fibrodisplasia osificante progresiva.

Radiografía: calcificaciones sobrepuestas a la columna y las costillas y calcificaciones que unen la región occipital con la columna cervical (Figura 3).

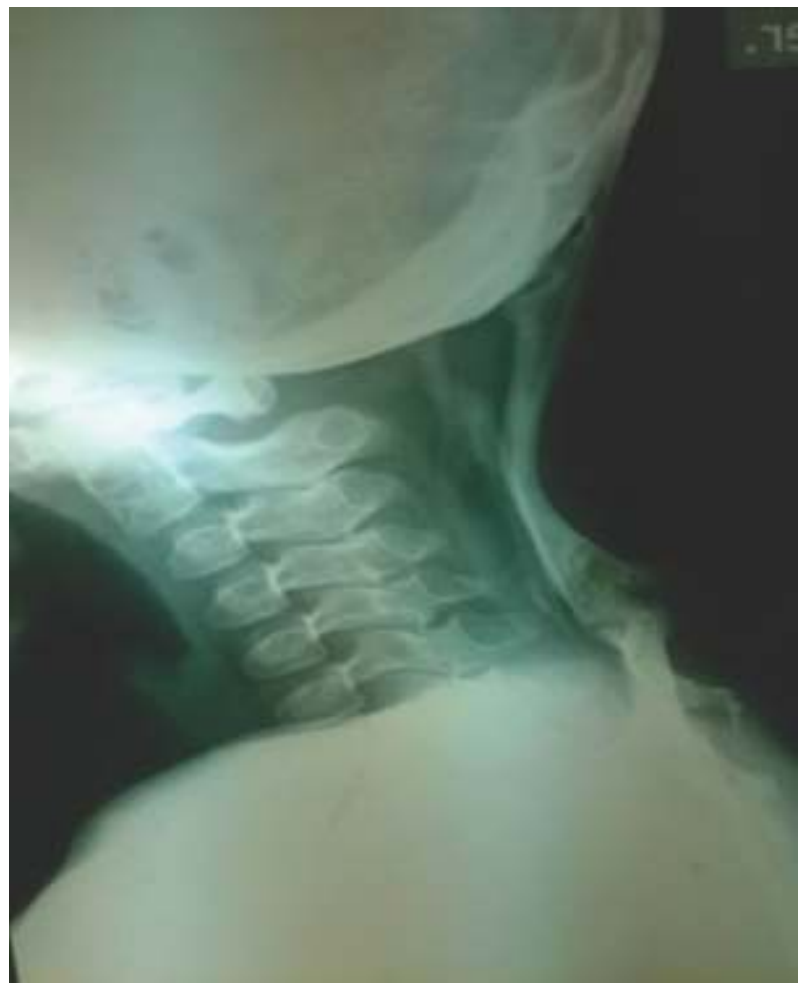

Figura 3. Rx lateral cervical. Calcificaciones que unen la región occipital con la columna cervical. 
Tomografía: Trazos extensos, confluentes de calcificaciones de las fascias intermusculares en cara posterior del cuello y tórax, alcanzan a fusionarse con los huesos del cráneo (calcificación tendinosa) (Figuras 4, 5 y 6). Por las características se plantea Fibrodisplasia Osificante progresiva (FOP).

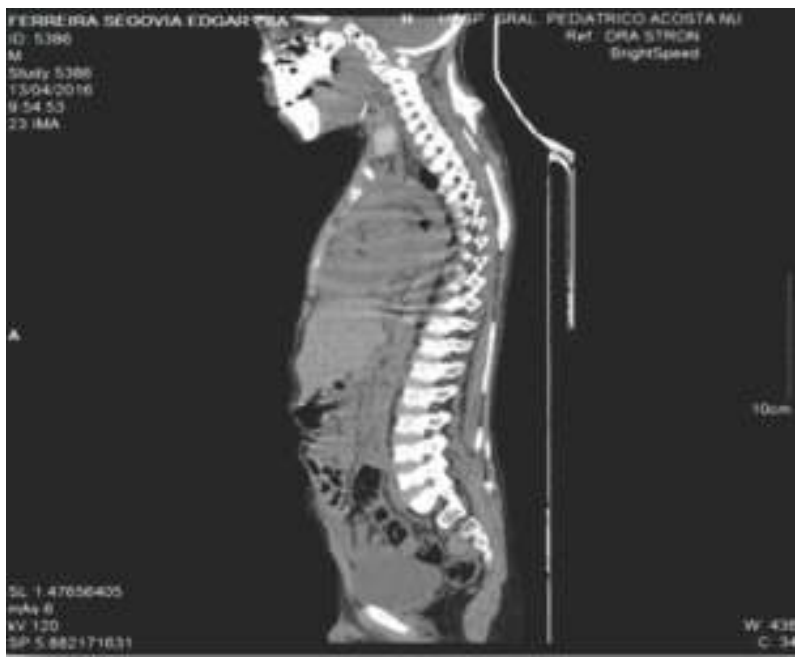

Figura 4. TAC LATERAL. Se observa imágenes hipodensas desde región cervical hasta región lumbar.

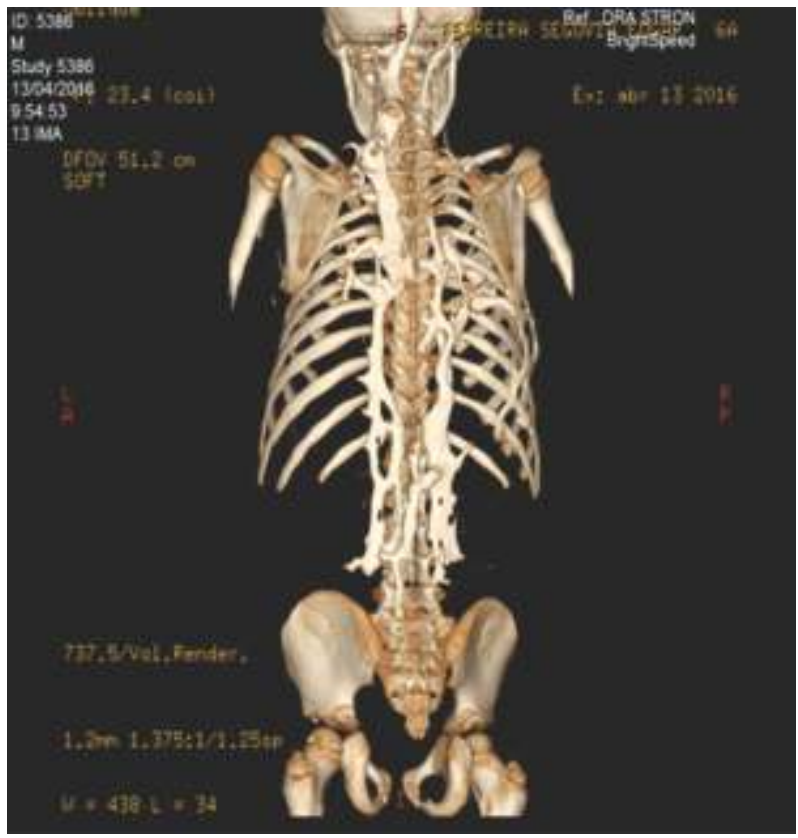

Figura 5. TAC POSTERIOR. Trazos extensos, confluentes de calcificaciones de las fascias intermusculares en cara posterior del cuello y tórax, alcanzan a fusionarse con los huesos del cráneo (calcificación tendinosa).

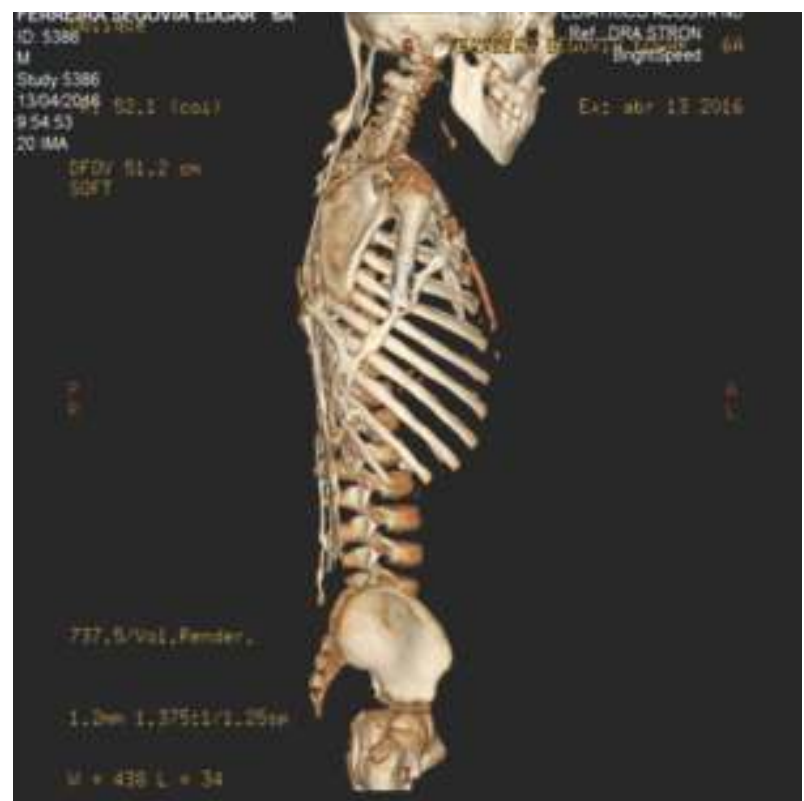

Figura 6. TAC LATERAL, formaciones lineales hiperdensas en forma perpendicular del tórax.

\section{DISCUSIÓN}

El diagnóstico de FOP se hace por clínica. Esta rara enfermedad tiene una prevalencia de 1:2.000.000 y es más frecuente en el sexo masculino (4:1). Los portadores presentan un aspecto normal, excepto por las malformaciones congénitas (primer metatarsiano). Los defectos del hállux son un signo temprano y patognomónico en todos los casos de fibrodisplasia osificante progresiva como se puede ver en el paciente en la figura 2. Durante la primera década de vida, la manifestación inicial consiste en edema y eritema sobre la masa muscular en donde se presente un trauma menor, simulando un proceso inflamatorio. En un lapso de tiempo de tres a seis meses, la masa se endurece y osifica ${ }^{(3,7)}$. Con frecuencia desencadenada por lesiones en el tejido blando. Estos brotes transforman los músculos esqueléticos, tendones, ligamentos, fascia, y aponeurosis, en huesos, limitando el movimiento, signos y síntomas evidenciados en la clínica del niño y que se pueden apreciar en la Figura 1.

Las radiografías simples pueden confirmar anomalías así como la presencia de osificación heterotópica ${ }^{(4)}$. Las lesiones óseas pueden notarse en 
las figuras 3 y 5 . La resección quirúrgica de las masas está contraindicada, pues empeora el estado clínico del paciente por la aparición de osificación local de los tejidos vecinos y el tratamiento farmacológico no ha logrado el control de la enfermedad ni mejoría del estado funcional de los pacientes afectados ${ }^{(2,3,8)}$. El pronóstico está determinado por la presencia de traumas mínimos, los cuales se asocian a mayores calcificaciones y limitaciones funcionales ${ }^{(9)}$. La mayoría sufre en las etapas finales una insuficiencia respiratoria restrictiva por la osificación de los músculos del tórax y por las graves deformidades de la columna, características que el paciente del caso clínico reportado no presentaba aún ${ }^{(2)}$.

\section{REFERENCIAS BIBLIOGRÁFICAS}

1. Márquez Capote E, Paz Presilla E, Pérez Sánchez G. Miositis osificante progresiva: presentación de un caso. MEDISAN. 2001;5(1):73-7.

2. Kaplan FO, Two FS, Shore S, Pignolo R J. The medical management of fibrodysplasia ossificans progressiva: current treatment considerations. Disponible en http://fun dacionfop.org.ar/wp-content/uploads/2015/09/themedical-management.pdf

3. Kaplan FS, Glaser DL, Hebela N, Shore EM. Heterotopic ossification. J Am Acad Orthop Surg. 2004; 12(2):116-25.

4. Scarlett RF, Rocke DM, Kantaine S, Patel JB, Shore EM, Kaplan FS. Influenza-like viral illnesses and flare-ups of fibrodysplasia ossificans progressive Clin Orthop. 2004; (423): 275-279.

5. O'Reilly M, Renton P. Metaphyseal abnormalities in fibrodysplasia ossificans progressiva. Br J Radiol. 1993, 66(782):112-6.
6. Moriatis JM, Gannon FH, Shore EM, Bilker W, Zasloff MA, Kaplan FS. Limb swelling in patients who have fibrodysplasia ossificans progressiva. Clin Orthop. 1997; (336):247-53.

7. Kaplan FS, Xu M, Glaser DL, Collins F, Connor M, Kitterman J. Early diagnosis of fibrodysplasia ossificans progressive. Pediatrics. 2008; 121(5):e1295-e1300 DOI: http://dx.doi.org/10.1542/peds.2007-1980Medline

8. Rogers, Geho. Fibrodysplasia ossificans progressiva. A survey of forty-two cases. J Bone Joint Surg Am. 1979; 61(6A):909-14.

9. Feldman G, Li M, Martin S. Fibrodysplasia Ossificans progresiva a Heritable Disorder of Sever Hetorotopic Ossification, maps to Human Chromosome 4q27-31. Am J Hum Genet, 2000; 66:128-135. 